\title{
A Rare Case of Brachydactyly Type A Presenting a Dilemma in Clinical Classification of the Subtype
}

\author{
G. I. Nambi ${ }^{1}$ \\ 1Plastic, Burns, Hand \& Microsurgical Services, Kavin Medical \\ Center, Erode, Tamil Nadu, India \\ ${ }^{2}$ Government Medical College \& ESI Hospital, Singanallur, \\ Coimbatore Tamil Nadu, India
}

\author{
T.K. Arudra Varanambigai
}

Indian J Plast Surg:2020;53:309-310

Brachydactyly is a condition characterized by congenital shortening of digits or toes, which occurs due to short phalanges, metacarpal or metatarsal bones. ${ }^{1}$ This condition may involve more than one digit or toe and depending on the involvement of the underlying bones and number of digits this condition, it is classified into five types (type A-type E). ${ }^{2}$ They are inherited as autosomal dominant, recessive, or sporadic varieties. In this report, a rare case of Brachydactyly type $A$ is presented, which had a variable presentation, causing difficulty in classifying the subtype.

A 30-year-old male presented with flexion deformity of the left little finger after a recent trauma. On examination, he was found to have an associated extensor injury from a previous trauma, but it was the short index finger that attracted the attention ( $\mathbf{- F i g s .} \mathbf{1}$ and $\mathbf{2}$ ) and further examination of the opposite hand, both feet and general physical examination did not reveal any abnormality. $\mathrm{X}$-ray of the hand revealed shortening of the middle phalanges of the left index finger, little finger and metacarpal bone of the left thumb with normal middle and ring fingers ( - Fig. 3). There was no history of similar hand or foot anatomical variations in his family members. The patient was explained about the variable anatomy and advised reconstruction of the little finger extensor tendon for which he never turned up. Retrospective literature search revealed that he was a rare case of Brachydactyly type $A$.

Brachydactyly type $A$ is characterized by short middle phalanges of the index, middle, ring, and little fingers. When the shortening of the middle phalanges of the index, middle and ring finger is associated with shortening of the proximal phalanx of the thumb, the condition is called as Brachydactyly type $\mathrm{A} 1{ }^{2}$ Isolated shortening of the middle phalanx of the index finger is known as Brachydactyly type A2 and isolated shortening of the middle phalanx of the little finger is known as Brachydactyly type A3 and in Brachydactyly type A4, there is shortening of the middle phalanges of the index and little fingers.

Brachydactyly type $\mathrm{B}^{2}$ is characterized by short or absent terminal phalanges with absence of nails from the index finger to the little finger. The thumb may or may not be involved,
Address for correspondence G.I. Nambi, MS, MCh, FICS, Plastic, Burns, Hand \& Microsurgical Services, Kavin Medical Center, Perundurai Road, Erode, Tamil Nadu, 638011, India (e-mail: nambi75@rediffmail.com).

and if involved, it is associated with flattening or duplication of the terminal phalanges.

Brachydactyly type $\mathrm{C}^{3}$ is characterized by a long ring finger and shortening of the rest of the digits due to shortening of middle or proximal phalanges and metacarpal bones.

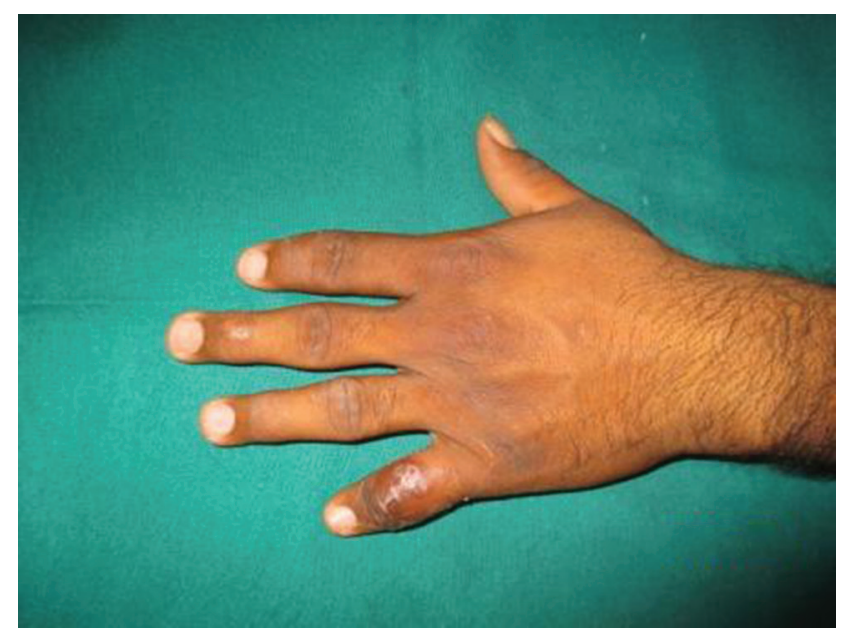

Fig. 1 Flexion deformity of the left little finger, with a scar over the dorsum of the proximal phalanx.

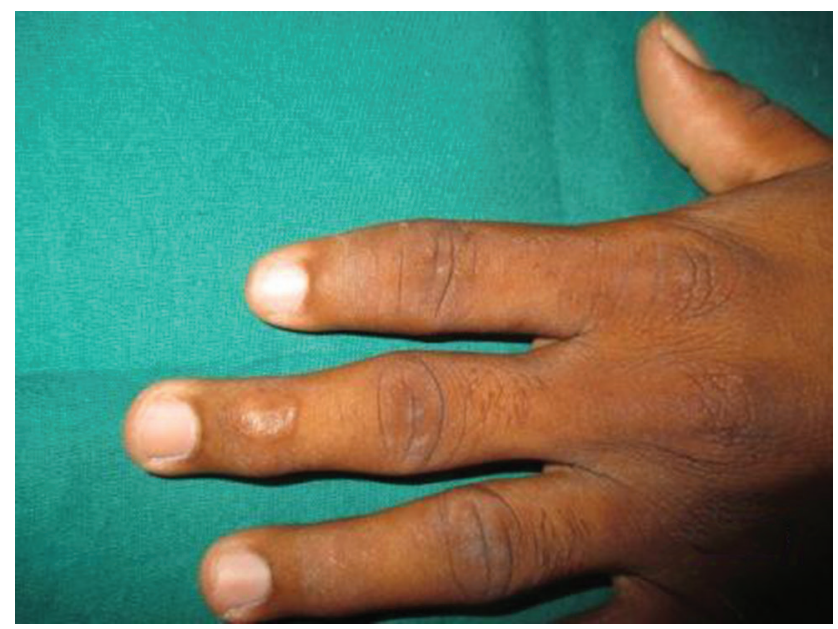

Fig. 2 Short left index finger.
License terms 


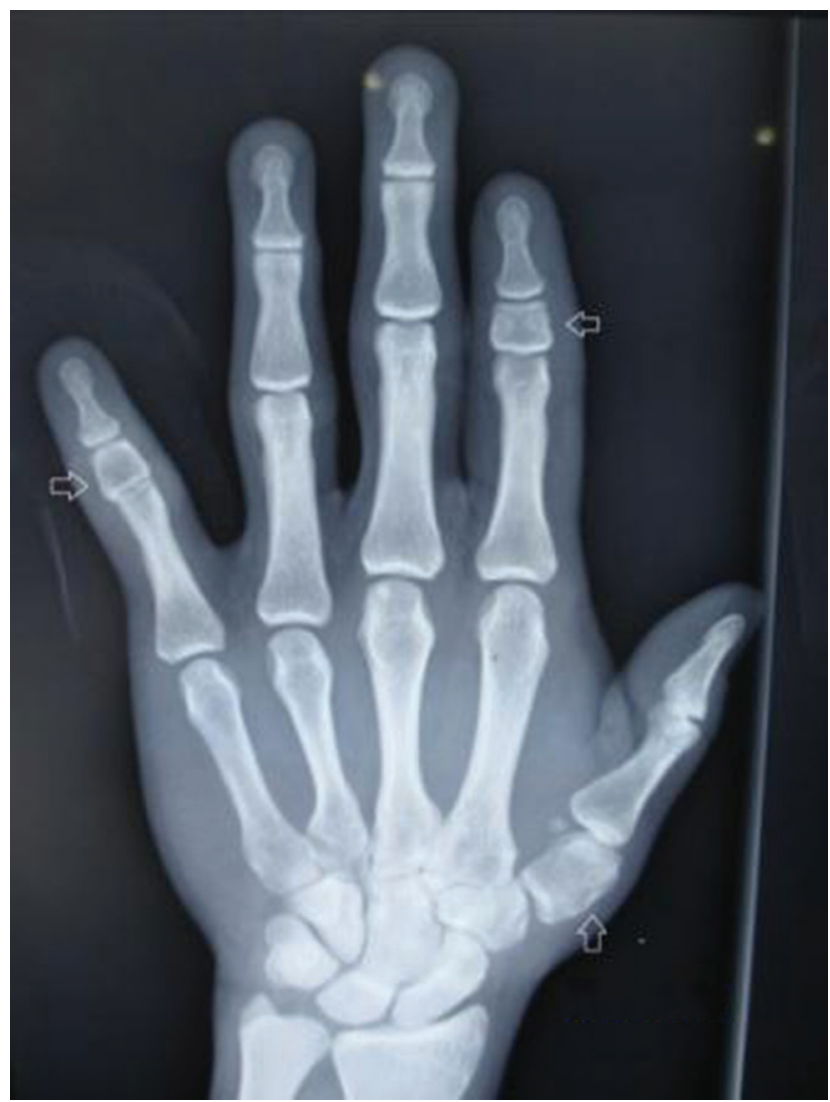

Fig. 3 X-ray of the left hand is suggestive of shortening of middle phalanges of the index and little fingers along with shortening of the thumb metacarpal.

In this type, the terminal phalanx is not involved in any of the digits, and there is thumb shortening due to short metacarpal bone.

Brachydactyly type $\mathrm{D}^{2}$ also known as stub thumb, is characterized by short terminal phalanx of the thumb.
This condition may be unilateral or bilateral, and the base of the distal phalanx of the thumb is broader than the head of the proximal phalanx. The rest of the digits are unaffected in type D.

Brachydactyly type $\mathrm{E}^{2}$ is characterized by shortening of the metacarpal bones with relatively normal phalanges. Another characteristic feature of this condition is the hyperextensibility of the hand joints.

In our case, there was shortening of the middle phalanges of the index and little fingers along with a short thumb metacarpal and normal ring and middle fingers. A presentation of this type would have classified it as type $\mathrm{C}^{3}$ due to the involvement of the thumb. However, it could not be done in this case, because the middle finger was normal and was the longest digit, while in type $C_{,}{ }^{2}$ the ring finger is the longest digit. This case could not be placed in any of the described subtypes of Brachydactyly type $A,{ }^{2}$ because of the involvement of the thumb metacarpal. Therefore, we conclude that this is a rare variety of Brachydactyly type A, presenting with a dilemma in subclassification between types $\mathrm{A} 2, \mathrm{~A} 3$ and $\mathrm{A} 4$.

\section{Conflicts of Interest}

None declared.

\section{Sources of Support}

None declared.

\section{Acknowledgments}

None.

\section{References}

1 Baraitser M, Burn J. Recessively inherited brachydactyly type C. J Med Genet 1983;20(2):128-129

2 Temtamy SA, Aglan MS. Brachydactyly. Orphanet J Rare Dis 2008;3:15

3 Fitch N. Classification and identification of inherited brachydactylies. J Med Genet 1979;16(1):36-44 